\title{
Remote sensing and in-situ measurements of tropospheric aerosol, a PAMARCMiP case study
}

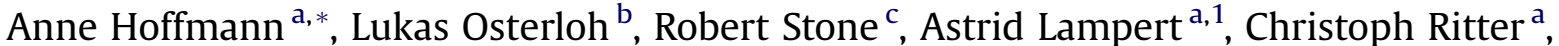 \\ Maria Stock $^{\mathrm{a}}$, Peter Tunved ${ }^{\mathrm{d}}$, Tabea Hennig ${ }^{\mathrm{d}}$, Christine Böckmann ${ }^{\mathrm{b}}$, Shao-Meng Li ${ }^{\mathrm{e}}$, \\ Kostas Eleftheriadis ${ }^{\mathrm{f}}$, Marion Maturilli ${ }^{\mathrm{a}}$, Thomas Orgis ${ }^{\mathrm{a}}$, Andreas Herber ${ }^{\mathrm{g}}$, \\ Roland Neuber ${ }^{a}$, Klaus Dethloff ${ }^{a}$ \\ ${ }^{a}$ Alfred Wegener Institute for Polar and Marine Research, Telegrafenberg A45, Potsdam, Germany \\ ${ }^{\mathrm{b}}$ University of Potsdam, Institute of Mathematics (IMP), Potsdam, Germany \\ ${ }^{\mathrm{C}}$ CIRES/NOAA Earth System Research Laboratory, 325 Broadway, Boulder, CO 80309, USA \\ d Department of Applied Environmental Science, Stockholm University, SE-106 91 Stockholm, Sweden \\ e Environment Canada, Toronto, Canada \\ ${ }^{\mathrm{f}}$ ERL, Demokritos National Center of Scientific Research, Institute of Nuclear Technology and Radiation Protection, Attiki, Greece \\ ${ }^{g}$ Alfred Wegener Institute for Polar and Marine Research, Bremerhaven, Germany
}

\section{A R T I C L E I N F O}

\section{Article history:}

Received 26 April 2011

Received in revised form

7 November 2011

Accepted 13 November 2011

\section{Keywords:}

Arctic

Aerosols

Lidar

Arctic haze

\begin{abstract}
A B S T R A C T
In this work, a closure experiment for tropospheric aerosol is presented. Aerosol size distributions and single scattering albedo from remote sensing data are compared to those measured in-situ. An aerosol pollution event on 4 April 2009 was observed by ground based and airborne lidar and photometer in and around Ny-Ålesund, Spitsbergen, as well as by DMPS, nephelometer and particle soot absorption photometer at the nearby Zeppelin Mountain Research Station.

The presented measurements were conducted in an area of $40 \times 20 \mathrm{~km}$ around Ny-Ålesund as part of the 2009 Polar Airborne Measurements and Arctic Regional Climate Model Simulation Project (PAMARCMiP). Aerosol mainly in the accumulation mode was found in the lower troposphere, however, enhanced backscattering was observed up to the tropopause altitude. A comparison of meteorological data available at different locations reveals a stable multi-layer-structure of the lower troposphere. It is followed by the retrieval of optical and microphysical aerosol parameters. Extinction values have been derived using two different methods, and it was found that extinction (especially in the UV) derived from Raman lidar data significantly surpasses the extinction derived from photometer AOD profiles. Airborne lidar data shows volume depolarization values to be less than $2.5 \%$ between $500 \mathrm{~m}$ and $2.5 \mathrm{~km}$ altitude, hence, particles in this range can be assumed to be of spherical shape. In-situ particle number concentrations measured at the Zeppelin Mountain Research Station at $474 \mathrm{~m}$ altitude peak at about $0.18 \mu \mathrm{m}$ diameter, which was also found for the microphysical inversion calculations performed at $850 \mathrm{~m}$ and $1500 \mathrm{~m}$ altitude. Number concentrations depend on the assumed extinction values, and slightly decrease with altitude as well as the effective particle diameter. A low imaginary part in the derived refractive index suggests weakly absorbing aerosols, which is confirmed by low black carbon concentrations, measured at the Zeppelin Mountain as well as on board the Polar 5 aircraft.
\end{abstract}

(c) 2011 Elsevier Ltd. All rights reserved.

\footnotetext{
* Corresponding author.

E-mail addresses: anne.hoffmann@awi.de (A. Hoffmann), lukas.osterloh@ googlemail.com (L. Osterloh), robert.stone@noaa.gov (R. Stone), astrid.lampert@tu-bs. de (A. Lampert), peter.tunved@itm.su.se (P. Tunved), shao-meng.li@ec.gc.ca (S.-M. Li), elefther@ipta.demokritos.gr (K. Eleftheriadis), andreas.herber@awi.de (A. Herber).

1 Now at: Institute of Aerospace Systems, Technische Universität Carolo-Wilhelmina zu Braunschweig, Hermann-Blenk-Str. 23, 38108 Braunschweig, Germany.
}

\section{Introduction}

The Arctic is a remote region with generally very low concentrations of aerosols. However, the concentration of especially accumulation mode aerosols and associated aerosol optical depth (AOD) annually peaks in the spring months March through April as a result of poleward aerosol transport. This increase in tropospheric aerosols is commonly referred to as Arctic haze (Shaw, 1995; Sirois and Barrie, 1999 and Quinn et al., 2007). It was first observed as 
a visible layer of unknown origin in the 50's by pilots crossing the American Arctic. Its anthropogenic origin was shown by Rahn et al., (1977) and Rahn (1981) and others about 35 years ago. A strong annual increase in particulate sulfates, with maximum values in March and April, has been monitored at different sites throughout the Arctic for almost 30 years (Barrie et al., 1981, Quinn et al., 2000). Arctic haze consists of well-aged aerosol of $0.2 \mu \mathrm{m}$ or less in diameter, i.e. dominated by the accumulation mode. Sulfate is the most abundant compound, but also nitrates, chlorides and carbonaceous compounds are present, e.g. a haze event in 2000 was characterized by a high mixing ratio of externally mixed soot particles (Yamanouchi et al., 2005). Arctic haze is assumed to mainly originate from long-range transported anthropogenic pollution from Europe and western Asia. Depending on the location of the polar front, effective meridional air mass exchange between the polar and mid-latitudes is possible. It has been shown that Arctic haze can get trapped for up to 15-30 days in late winter (Quinn et al., 2007). Additionally, biomass burning events are considered to contribute to Arctic haze (Law and Stohl, 2007, Warneke et al., 2010). Vertically and spatially highly inhomogeneous haze layers have been observed frequently above Spitsbergen, as reported by Gerding et al. (2004), Yamanouchi et al. (2005), Stohl (2006) and Hoffmann et al. (2009). Due to the large abundance of accumulation mode sized particles, Arctic haze layers are very efficient in scattering solar radiation. The presence of light absorbing material such as soot also enhances the absorption during periods of Arctic haze.

The airborne research project PAMARCMiP (Polar Airborne Measurements and Arctic Regional Climate Model Simulation Project) studied the meteorology, air quality and sea ice thickness in the Arctic (Stone et al., 2010). Over the Arctic, little information is available on the spatial distribution of atmospheric aerosols, e.g. soot, and clouds and on their radiative impact (Liu et al., 2010). Data obtained with several instruments on board the Polar 5 aircraft are compared to ground based remote sensing data from the French German Arctic Research Base, AWIPEV $\left(11.92^{\circ} \mathrm{E}, 78.92^{\circ} \mathrm{N}\right)$ as well as continuous in-situ data collected at the Zeppelin Mountain Research Station $\left(11.89^{\circ} \mathrm{E}, 78.91^{\circ} \mathrm{N}\right)$, located in and close to Ny-Ålesund.

The AWIPEV Research Base is operated by the Alfred Wegener Institute for Polar and Marine Research (AWI) and the Institut polaire français Paul-Emile Victor (IPEV). It facilitates a uniquely well equipped atmospheric laboratory, which provides long term remote sensing technologies including lidar and sun photometer as well as atmospheric monitoring using balloon soundings. These technologies can be combined to characterize the Arctic atmosphere. In the first week of April 2009, the AOD measured by ground based sun photometer was relatively high and, as confirmed by lidar data, concentrated within the lowest few kilometers of the atmosphere. Within this period, the largest AOD of up to 0.12 at $532 \mathrm{~nm}$ was measured on 4 April 2009. Coincidentally, this day was one of the two days of the PAMARCMiP campaign, where instrument comparison flights in the Ny-Ålesund vicinity were performed. These data are used for a remote sensing and in-situ intercomparison, which is important to better understand the aerosol radiative forcing. Closure studies between experiments measuring optical and in-situ aerosol properties are sparse so far; Wandinger et al., (2002) describes a case from central Europe. However, we are not aware of such intercomparisons for Arctic aerosols so far.

\section{Methods}

Ground based data obtained at the AWIPEV Research Base in Ny-Ålesund and the Zeppelin Mountain Research Station are compared to airborne data collected during a comparison flight of the research aircraft Polar 5. From 10:00 to 12:00 UTC, Polar 5 circled the Ny-Ålesund vicinity at altitudes from $100 \mathrm{~m}$ to $3600 \mathrm{~m}$ above ground. The detailed flight pattern can be seen in Fig. 1 with the flight sections, in which the different instruments on board were active, being color coded. The average speed of the airplane was $50 \mathrm{~m} \mathrm{~s}^{-1}$. An overview of the used in-situ and remote sensing instruments is given in Table 1 and described in the following section.

\subsection{Meteorological soundings}

Vaisala radiosondes are routinely launched from Ny-Ålesund since October 1991 in order to characterize the vertical thermal, dynamical and moisture structure of the Arctic atmosphere. On 4 April 2009, the standard Vaisala RS-92 radiosonde was launched at 11:44 UTC to optimize the temporal difference to the Polar 5 overflight. Thus, vertical profile data of temperature, relative humidity, wind speed and wind direction are available from $11 \mathrm{~m}$ above sea level well into the stratosphere.

In addition, a dropsonde was launched from the aircraft at $12.50^{\circ} \mathrm{E}, 78.82^{\circ} \mathrm{N}$ (about $17 \mathrm{~km}$ from $\mathrm{Ny}$-Ålesund) to measure the same atmospheric state variables from flight altitude down to the ground. This Vaisala RD93 sonde was dropped about $3 \mathrm{~km}$ above the surface at 10:58 UTC, landing at about $350 \mathrm{~m}$ above sea level on top of the Kongsvegen glacier. The transmitted data was received by a system on board Polar 5 .

\subsection{Lidar}

Two lidar systems were used for this study: the ground based Koldewey Aerosol Raman Lidar (KARL), which is a multi-wavelength Raman lidar and the nadir looking Airborne Mobile Aerosol Lidar (AMALi) on board the research aircraft Polar 5.

\subsubsection{KARL}

The KARL is housed in the Atmospheric Observatory of the AWIPEV Research Base and is operated as a tropospheric Raman Lidar since its first deployment in 2001 on a regular basis and in
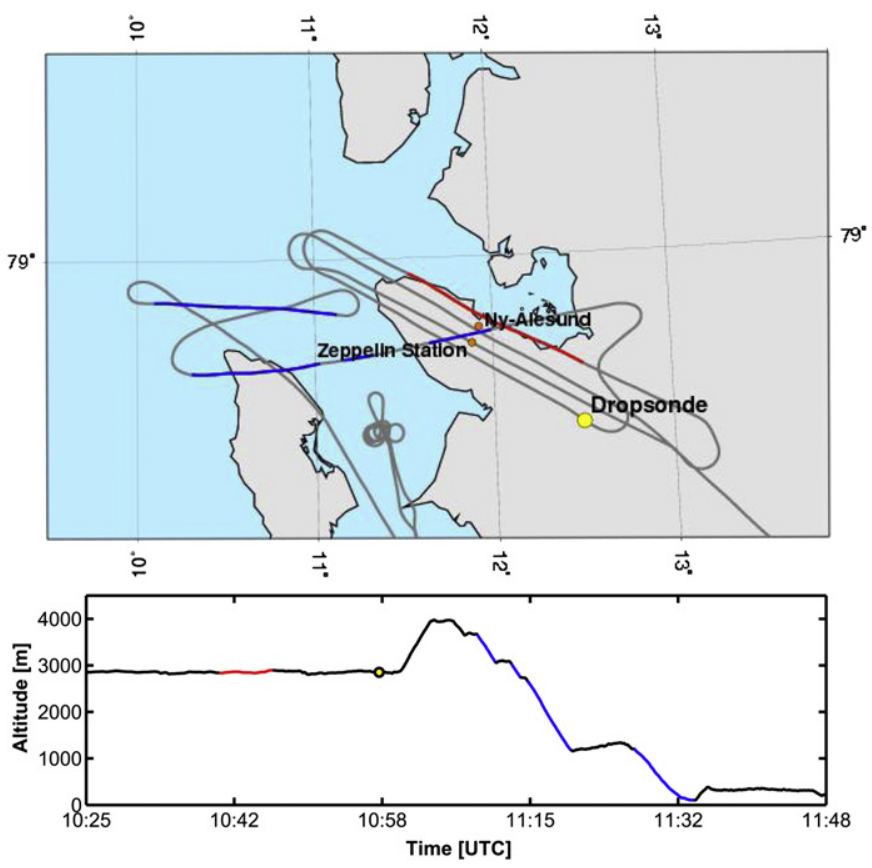

Fig. 1. Flight patterns of the POLAR 5 research aircraft on 4 April 2009. Stretches, where the different instruments were in operation are color coded: AMALi (red), sun photometer (blue), and dropsonde (yellow). 
Table 1

Overview of the instruments, measurement errors and purposes used in this work.

\begin{tabular}{|c|c|c|c|c|}
\hline & Instrument [location] & Direct quantity [error] & Deduced quantity [error] & Aim \\
\hline \multirow[t]{5}{*}{ Remote, ground: } & Radiosonde [Ny-Ålesund] & $\mathrm{T}(\mathrm{z})[0.5 \mathrm{~K}]$ & Boundary layer altitude & Judge stability and comparability \\
\hline & & $\mathrm{Rh}(\mathrm{z})[5 \%]$ & & of meteorological conditions \\
\hline & & Wind $\left[0.3 \mathrm{~m} \mathrm{~s}^{-1}, 5^{\circ}\right]$ & & \\
\hline & KARL lidar [Ny-Ålesund] & $\begin{array}{l}\text { Backscatter and extinction } \\
\text { coefficients }[10 \%, 20 \%]\end{array}$ & $\begin{array}{l}\text { Size distribution } \\
\text { [20\% for particle number] } \\
\text { and refractive index }[ \pm 0.05]\end{array}$ & Compare to in-situ data \\
\hline & Photometer [Ny-Ålesund] & Aerosol optical depth [0.01] & & $\begin{array}{l}\text { Check KARL lidar, judge temporal } \\
\text { fluctuation of aerosol load }\end{array}$ \\
\hline \multirow[t]{5}{*}{ Remote, airborne: } & Dropsonde [Polar 5 aircraft] & $\mathrm{T}(\mathrm{z})[0.5 \mathrm{~K}]$ & & Justify comparability \\
\hline & & $\operatorname{Rh}(z)[5 \%]$ & & to Ny-Ålesund data \\
\hline & & Wind $\left[0.3 \mathrm{~m} \mathrm{~s}^{-1}, 5^{\circ}\right]$ & & \\
\hline & AMALi lidar [Polar 5 aircraft] & $\begin{array}{l}\text { Backscatter coefficients, } \\
\text { depolarization }[25 \%, 10 \%]\end{array}$ & & Shape of aerosol, profile below $800 \mathrm{~m}$ \\
\hline & Photometer [Polar 5 aircraft] & Aerosol optical depth [0.01] & Extinction coefficient [20\%] & $\begin{array}{l}\text { Compare to KARL lidar and } \\
\text { Zeppelin station }\end{array}$ \\
\hline \multirow[t]{5}{*}{ In-situ, ground: } & DMPS [Zeppelin] & $\begin{array}{l}\text { Mobility distribution } \\
\text { [12.5\% for particle number] }\end{array}$ & $\begin{array}{l}\text { Size distribution } \\
\text { [12.5\% for particle number] }\end{array}$ & Compare to KARL lidar \\
\hline & Nephelometer [Zeppelin] & $\begin{array}{l}\text { Scattering and backscatter } \\
\text { coefficient }[2 \%]\end{array}$ & Single scattering albedo [0.02] & Compare to lidar \\
\hline & PSAP [Zeppelin] & Absorption [20\%] & Single scattering albedo [0.02] & Compare to aircraft \\
\hline & SEQ [Zeppelin] & $\begin{array}{l}\text { Organic and elemental } \\
\text { carbon }[10 \%]\end{array}$ & & Representativeness on weekly scale \\
\hline & Aethalometer [Zeppelin] & Extinction coefficient [ $>6 \%]$ & Absorption, black carbon [15\%] & Compare to aircraft \\
\hline In-situ, airborne: & $\begin{array}{l}\text { Single particle soot photometer } \\
\text { [Polar } 5 \text { aircraft] }\end{array}$ & Absorption coefficient [10\%] & Black carbon concentration [20\%] & Compare to Zeppelin \\
\hline
\end{tabular}

numerous field campaigns. The system has received several modifications, the latest one being an upgrade to a combined tropospheric-stratospheric system in fall 2008. From spring 2009 on, it contains a larger telescope in a coaxial, single-telescope setup. A Spectra Quanta-Ray PPO 290-50 Nd:YAG laser with output wavelengths of 355,532 and $1064 \mathrm{~nm}$ at a repetition rate of $50 \mathrm{~Hz}$ is used. Laser light scattered by molecules and aerosols produces a return signal at the output wavelengths and an additional, much weaker and molecule specific signal because of Raman scattering at shifted wavelengths. The return signals at the output wavelengths, the Raman shifted wavelengths for nitrogen and water vapor as well as the parallel polarized signal of the 355 and $532 \mathrm{~nm}$ signal are collected by a 0.7 m diameter, variable field of view $(0.8-2.5 \mathrm{mrad})$ parabolic mirror. The telescope output is collimated and then split among four quartz fibers using dichroic beam splitters. Further wavelengths separation is done behind the fibers before the light is focussed to eight photomultiplier tubes and an avalanche photo diode in the case of the $1064 \mathrm{~nm}$ channel. The maximum height resolution is $7.5 \mathrm{~m}$; the temporal resolution is set to $1.5 \mathrm{~min}$. A full description of the system can be found in Hoffmann et al. (2010).

On 4 April, KARL was operated from 4:37 to 24:00 UTC with only short breaks due to calibration procedures. In order to reduce the overlap height, the field of view was set to $1.71 \mathrm{mrad}$ and the telescopes focus was set to the near field during the time interval, in which Polar 5 circled the area. Data are averaged to $60 \mathrm{~m}$ altitude resolution and $1.5 \mathrm{~min}$ temporal resolution. For the comparison with photometer data 20 data sets recorded between 11:30 and 12:00 UTC - close to the balloon launch and the Polar 5 overpass were selected. Due to technical reasons, depolarization measurements are not available during the PAMARCMiP campaign.

\subsubsection{AMALi}

On board the Polar 5 was the Airborne Mobile Aerosol Lidar (AMALi) system, developed by AWI Potsdam, which operates at wavelengths of $532 \mathrm{~nm}$ and $355 \mathrm{~nm}$ (Stachlewska et al., 2010). It utilizes an Nd:YAG pulsed laser and can be operated in the Polar 5 aircraft in either nadir or zenith configuration. The data on 4 April were recorded in the nadir position. The vertical resolution of the data is $7.5 \mathrm{~m}$, the horizontal resolution depends on the aircraft speed. Data are averaged over $15 \mathrm{~s}$, which translates to a horizontal resolution of ca. $750 \mathrm{~m}$. Backscatter profiles as well as profiles of the linear volume depolarization ratio at $532 \mathrm{~nm}$ were obtained from 10:05 to 11:00 UTC. A period of $6 \mathrm{~min}$ (10:40-10:46 UTC) was selected, when no clouds or mountains were present and the signal penetrated to the ground. The data can be evaluated between the ground surface and $250 \mathrm{~m}$ below cruising altitude, i.e. $2.8 \mathrm{~km}$ altitude on 4 April.

\subsection{Photometer}

\subsubsection{Airborne photometer}

During the Polar 5 flight, spectral AOD data were derived from measurements made using an 8 channel Sun photometer system developed at the U. S. National Oceanic and Atmospheric Administration (NOAA) and the Institute of Atmospheric Sciences Climate - National Research Council (ISAC-CNR), Italy. It measures spectral irradiance at nominal, central wavelengths of 368, 412, 500, $610,675,778,862$ and $1050 \mathrm{~nm}$. A detailed description of the system can be found in Stone et al. (2010). The profile data used in this study were recorded from 11:14 to 11:55 UTC. Additionally, GPS position and altitude along the flight track were recorded. The analyses methods employed are outlined in Stone et al. (2002, 2010). They include cloud screening to minimize the influence of thin clouds as well as corrections for ozone and $\mathrm{NO}_{2}$ attenuation. The accuracy of AOD retrievals obtained during PAMARCMIP is estimated to be within \pm 0.005 for wavelengths in the range from $412 \mathrm{~nm}$ to $862 \mathrm{~nm}$ (Stone et al., 2010).

\subsubsection{Ground based photometer}

The AOD at Ny-Ålesund was measured using a sun photometer type SP1A produced by Dr. Schulz and Partner GmbH. It has a field of view of $1^{\circ}$ and covers a spectral range from $350 \mathrm{~nm}$ to $1050 \mathrm{~nm}$ in 17 channels, including the wavelengths at which the sun photometer on board of Polar 5 operates. A detailed description of the instrument and the performed measurements in Ny-Ålesund can be found in Herber et al. (2002). 


\subsection{In-situ instruments}

\subsubsection{Zeppelin Mountain Research Station}

In-situ instruments were operated simultaneously at the Zeppelin Mountain Research Station. It is situated on a mountain ridge, $474 \mathrm{~m}$ above sea level and $1.7 \mathrm{~km}$ south of Ny-Ålesund. The station is usually unaffected by local sources due to anthropogenic activities in and around Ny-Ålesund, and mostly below the boundary layer cloud top, hence, the observations at the station are representative for Arctic boundary layer conditions (Ström et al., 2003).

The Department of Applied Environmental Science (ITM) at Stockholm University continuously operates a number of instruments that are used in this study. The aerosol number size distribution at the Zeppelin Mountain is observed using a Differential Mobility Particle Sizer (DMPS) utilizing a medium size Hauke DMA (Knutson and Whitby, 1975). After classification according to size in the DMA the particles are counted using a СРC3010. The size range observed by the instrument covers sizes between 10 and $790 \mathrm{~nm}$, using a dlogDp of 0.05 , i.e. 20 bins per decade. The DMPS further uses a closed-loop sheath-air circulation system. The aerosol sample flow is $1 \mathrm{~L} \mathrm{~min}{ }^{-1}$, with the sheet air flow set to $5.5 \mathrm{~L} \mathrm{~min}^{-1}$. The mobility distribution measured by the DMA is inverted to a number distribution assuming a Fuchs charge distribution (Wiedensohler, 1988). Aerosol light scattering is measured using a TSI 3563 integrating nephelometer. The nephelometer observes total scattering and backscattering at three different wavelengths (450 nm, $550 \mathrm{~nm}$ and $700 \mathrm{~nm}$ ). The aerosol light absorption is measured using a custom-built Particle Soot Absorption Photometer (PSAP). The PSAP, corrected by spot size and filter loading, delivers observations of the particle light absorption coefficient $\sigma_{\mathrm{ab}}$ at a single wavelength of $525 \mathrm{~nm}$.

At Zeppelin Mountain the carbon content in the aerosol particles is determined using different methods. For the investigation of organic carbon (OC) and elemental carbon (EC) concentrations, samples are collected using a Leckel sequential sampler SEQ 4750 which is working according to the standard CEN EN 12341. The sample flow is $2.3 \mathrm{~m}^{3} \mathrm{~h}^{-1}\left(38 \mathrm{~L} \mathrm{~min}^{-1}\right)$ and the filter medium is a quartz filter. The collected samples are analyzed using a OC/EC sunset lab from Sunset laboratory cooperation following the NIOSH standard procedure (NIOSH (1999). Method 5040 Issue 3). Due to the comparatively low particle mass concentrations found in the Arctic a sample time of one week per sample is necessary.

$\mathrm{BC}$ measurements at a higher temporal resolution are obtained by means of a Magee Sci., 7 wavelength aethalometer (Eleftheriadis et al., 2009), which measures attenuation of light from a source illuminating aerosol loaded filters at seven wavelengths. Also, the absorption coefficient can be obtained. It should be noted that the calculated BC is just a rough estimate of actual black carbon content and should be considered as an apparent concentration only. In our study we estimated the BC using a site-specific mass absorption efficiency of $15.9 \mathrm{~m}^{2} \mathrm{~g}^{-1}\left( \pm 0.7 \mathrm{~m}^{2} \mathrm{~g}^{-1}\right)$ (Eleftheriadis et al., 2009). This number is nevertheless somehow uncertain as a precise value depends on the chemical composition. The mass concentrations we derive from applying this factor are thus to be considered as so called equivalent black carbon (EBC). Other absorbing species likely exist as well such as mineral dust and brown carbon, which will influence the absorption and thus the correctness of the EBC calculations in representing actual BC concentrations.

\subsubsection{Airborne measurements}

On board the Polar 5, a Single Particle Soot Photometer (SP2) was installed and run by Environment Canada. It measures the size segregated concentration of $\mathrm{BC}$ by laser-induced incandescence using continuum laser.

\subsection{Microphysical inversion tool for spherical particles}

An algorithm for the retrieval of the size distribution, and thus, other relevant microphysical properties of aerosol such as the effective diameter, from multi-wavelength lidar data is used. The effective diameter is defined as:

$d_{\mathrm{eff}}=2 \cdot \frac{\int r^{3} n(r) d r}{\int r^{2} n(r) d r}$

The basic equations are considered as a linear ill-posed problem and solved using a regularization method consisting of spline collocation and a Padé type iteration (Böckmann and Kirsche, 2006) method which employs an adaptive strategy for the spline base points and projection onto the space of non-negative functions (Osterloh and Böckmann, 2009). The extinction and backscatter efficiencies needed for the inversion process are calculated via Mie theory. The problem is split into a series of linear problems, which calculate the microphysical inversion for every possible complex refractive index from a predefined grid (Osterloh et al., 2009). At each point of the grid, the residual error is calculated, and the refractive index with the lowest residual error chosen as the reconstruction value. Volume size distributions are reconstructed instead of the number distribution for numerical stability reasons. Note that all relevant concentrations and the effective diameter can be directly calculated from the distributions; simple integrations are required for that task.

For the lidar data used in this work we found errors of $5 \%$ for the distribution width and the effective radius and $20 \%$ for the aerosol number concentration (see also Table 1 ).

\section{Analyses}

The enhanced aerosol loading on April 4th is illustrated in Fig. 2, where the mean backscatter ratio (ratio of the backscattering by particles to total backscattering) obtained in two cloud-free periods in March 2007 and April 2009 is compared to the backscatter ratio as measured on 4 April 2009.

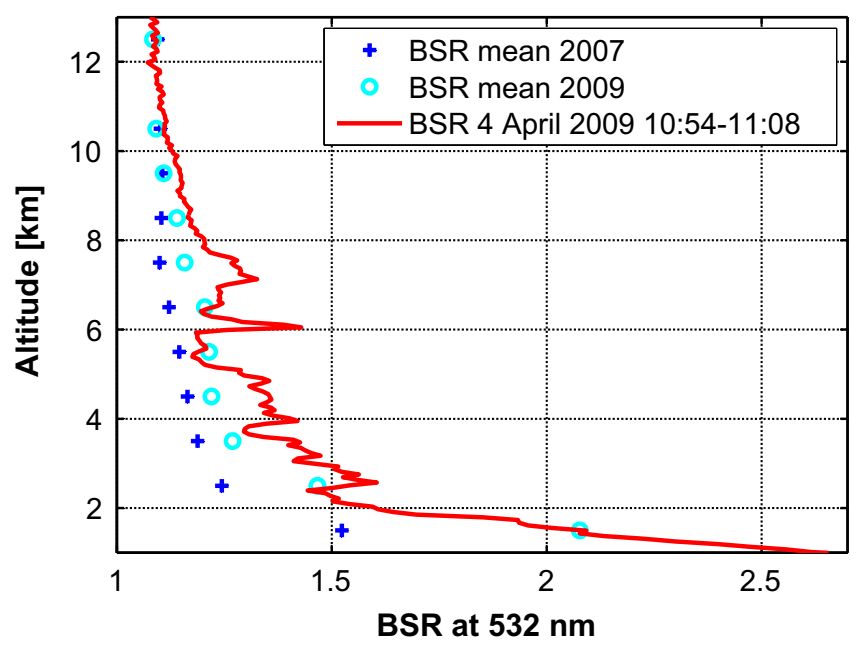

Fig. 2. Backscatter ratio (BSR) at $532 \mathrm{~nm}$ as measured with KARL in two eight day periods: 12-19 March 2007 and 30 March-6 April 2009 and on 4 April 2009. Given are 1-km means of BSR for cloud-free lidar data obtained within $31 \mathrm{~h}$ on six days in 2007 and $71 \mathrm{~h}$ on eight days in 2009. Data obtained on 4 April is averaged temporally from 10:54 to $11: 08$ UTC and to $60 \mathrm{~m}$ intervals vertically. 


\subsection{Meteorological situation}

The radiosonde and the dropsonde were started within a temporal interval of $45 \mathrm{~min}$ and with a spatial distance of about $17 \mathrm{~km}$. The radiosonde features significant changes at two altitudes, which are visualized in Fig. 3 (blue curves). Up until just below $500 \mathrm{~m}$ above ground the wind direction is very stable with easterly winds above $5 \mathrm{~m} \mathrm{~s}^{-1}$ and the water vapor mixing ratio is constant at $0.7-0.8 \mathrm{~g} \mathrm{~kg}^{-1}$. Around $500 \mathrm{~m}$ altitude, the potential temperature increases abruptly and within a second interval of constant potential temperature up to about $1100 \mathrm{~m}$ above ground the wind direction turns to northerly winds at lower wind speeds of $3-4 \mathrm{~m} \mathrm{~s}^{-1}$. The mixing ratio is still at $0.7-0.8 \mathrm{~g} \mathrm{~kg}^{-1}$ dropping to lower values at around $1100 \mathrm{~m}$, where a second increase of the potential temperature is observed. Obviously, the lower troposphere is stratified in a two-layer-structure, with the Zeppelin Mountain Research Station being situated just at the transition altitude. The potential temperature is almost constant below $450 \mathrm{~m}$ and between 500 and $1000 \mathrm{~m}$, which allows vertical mixing within each of the two layers. The tropopause altitude is determined to $7.73 \mathrm{~km}$, the prevailing wind direction throughout the troposphere with the exception of the lowermost $1000 \mathrm{~m}$ is north, which coincides with the air trajectory origin given below. The meteorological data obtained at the Zeppelin Mountain were averaged over $1 \mathrm{~h}$ from 11:00 to 12:00 (Fig. 3, green stars). Temperature and wind speed are similar to the radiosonde data, the relative humidity was only slightly larger with more than $60 \%$ and the wind came from the southeast. From these data, the Zeppelin Mountain Research Station was situated at the transition zone between the two layers.

The dropsonde (red curves in Fig. 3) notes a temperature inversion between 800 and $1000 \mathrm{~m}$ ASL (above sea level) with a drop in wind speed above the inversion. This is a few hundred meters higher than the same feature above Ny-Ålesund but can be addressed to the location of the dropsonde above a glacier, where it landed at about $300 \mathrm{~m}$ above sea level. The wind direction measured by the airplane instrumentation (not shown) also showed a change in wind direction between 650 and $600 \mathrm{~m}$ from southeast to northwest. All meteorological data were taken over a temporal range of a few hours and a spatial range of about $60 \mathrm{~km}$, hence, the similarities of the results indicate a very stable stratification of the boundary layer and the lower troposphere.

5-day backward air trajectories have been calculated with the Pole-Equator-Pole-Tracer model (Orgis et al., 2009) at 950, 850, 700 and $500 \mathrm{hPa}$, every $30 \mathrm{~min}$ from the airplane location as well as from Ny-Ålesund. For further analysis, the 12:00 UTC trajectories ending at Ny-Ålesund are considered, since most measurements were conducted around that time and the airplane was in the Ny-Ålesund area. However, the results are very stable over time and space with the predominant air mass origin at all pressure levels being the Central Arctic with no significant lifting or sinking of the air masses (cf. Fig. 4). The high-pressure system above the pole was temporally very stable from the end of March and through the first week of April.

\subsection{Backscatter and volume depolarization}

For the KARL data, aerosol backscatter coefficients at 355 and $532 \mathrm{~nm}$ are determined independently from elastic and inelastic $\left(\mathrm{N}_{2}\right.$ Raman) backscatter signals (Ansmann et al., 1992). Aerosol backscattering at $1064 \mathrm{~nm}$ is calculated according to the Klett algorithm, using a lidar ratio (extinction to backscatter ratio LR) of $20 \mathrm{sr}$ (Klett, 1981). Profiles of the molecular backscatter coefficient are calculated from the density profile obtained from the meteorological sounding. KARL data is neglected below $800 \mathrm{~m}$ due to an incomplete overlap function. The AMALi data has been calculated using the Klett approach with an LR of $20 \mathrm{sr}$ at $532 \mathrm{~nm}$ wavelength. a

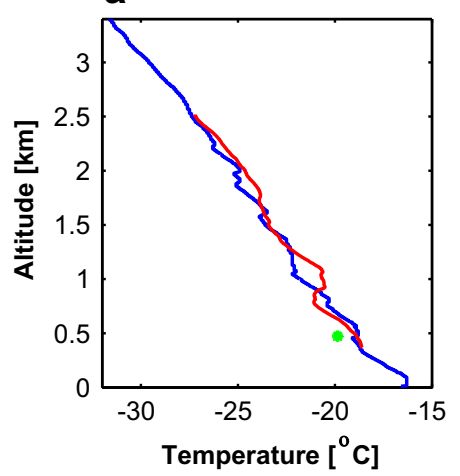

d

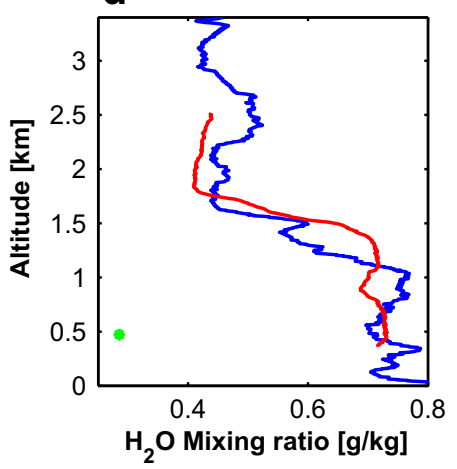

b

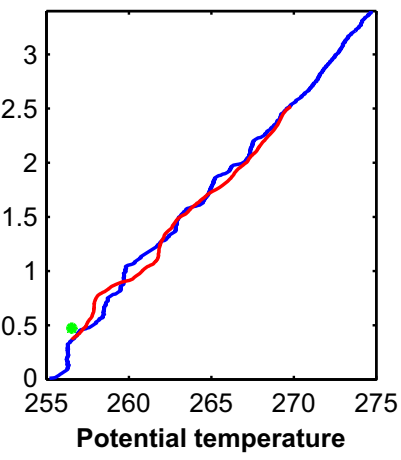

e

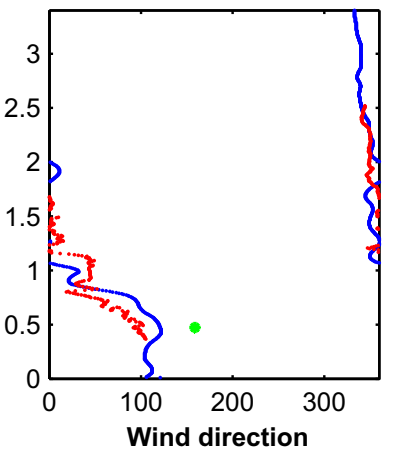

C

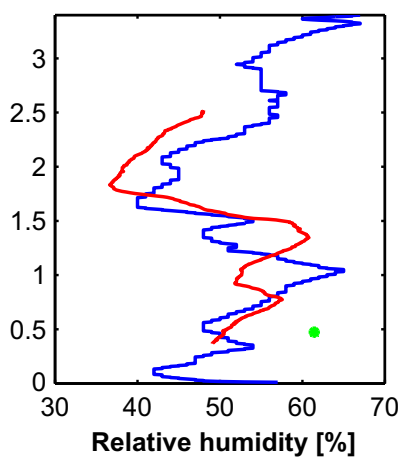

f

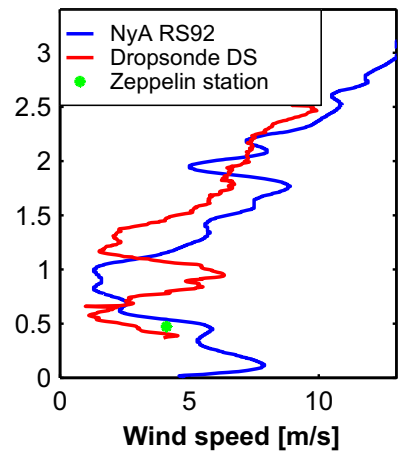

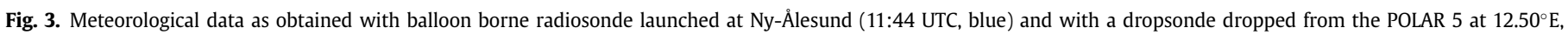
$78.82^{\circ} \mathrm{N}$ (10:58 UTC, red). Data obtained at the Zeppelin Mountain Research Station was averaged from 11:00 to 12:00 UTC and is shown in green. 

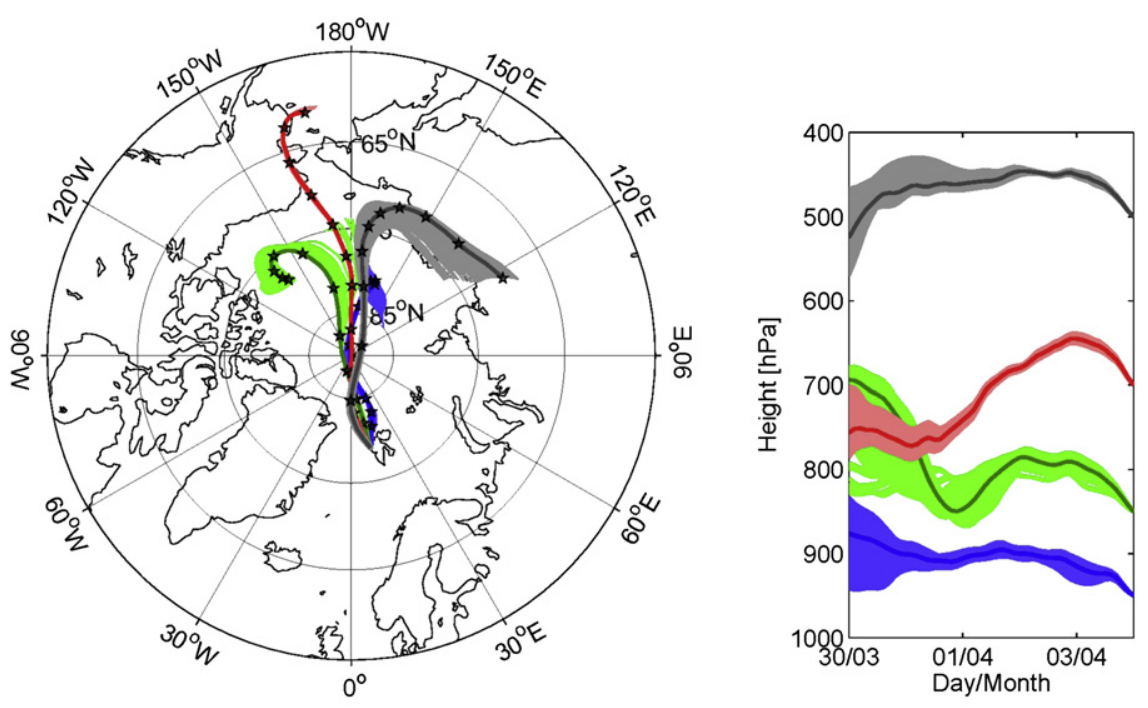

$950 \mathrm{hPa} 850 \mathrm{hPa} 700 \mathrm{hPa} 500 \mathrm{hPa}$

Fig. 4. 5-day backward ensemble trajectories calculated with the PEP-Tracer model at 950, 850, 700 and 500 hPa, at 12:00 UTC from Ny-Ålesund, stars mark 12 h intervals.

Volume depolarization, which measures the asphericity of the scattering particles, is calculated as the ratio of the perpendicular and parallel lidar signals. It is normalized to the molecular value of 0.014 between 1.0 and $2.3 \mathrm{~km}$. An overview of the backscatter coefficient during the day is given in Fig. 5. The aerosol backscattering profiles at 355 and $532 \mathrm{~nm}$ is given in Fig. 6(a); the AMALi volume depolarization ratio is given in Fig. 6(d).

\subsection{Aerosol optical depth}

The ground based sun photometer at Ny-Ålesund operates at wavelengths close to the elastic lidar wavelengths. AOD data is averaged over a 1-h time period (12:00-13:00 UTC) and yields values of 0.19 at $354 \mathrm{~nm}, 0.12$ at $532 \mathrm{~nm}$ and 0.04 at $1046 \mathrm{~nm}$ $( \pm 0.01)$. For the airborne sun photometer, extrapolation to the lidar wavelengths is performed by calculating the Ångström coefficient between the 412 and 610 -nm channel, which varies between -1.6 and -1.3 . The AOD, as measured at the lowest aircraft cruising altitude of $100 \mathrm{~m}$ above sea level, is determined to $0.23( \pm 0.03)$ at $355 \mathrm{~nm}$ and $0.14( \pm 0.02)$ at $532 \mathrm{~nm}$. Despite the fact that the data were obtained in up to $40 \mathrm{~km}$ distance, where the topography and hence the boundary layer height and structure can differ significantly, these values are only slightly larger than the ground based photometer AOD. Due to the spatial distance of the measurements and small scale variability characterizing both the AOD profiles as well as the lidar profiles, the results need to be smoothed vertically.

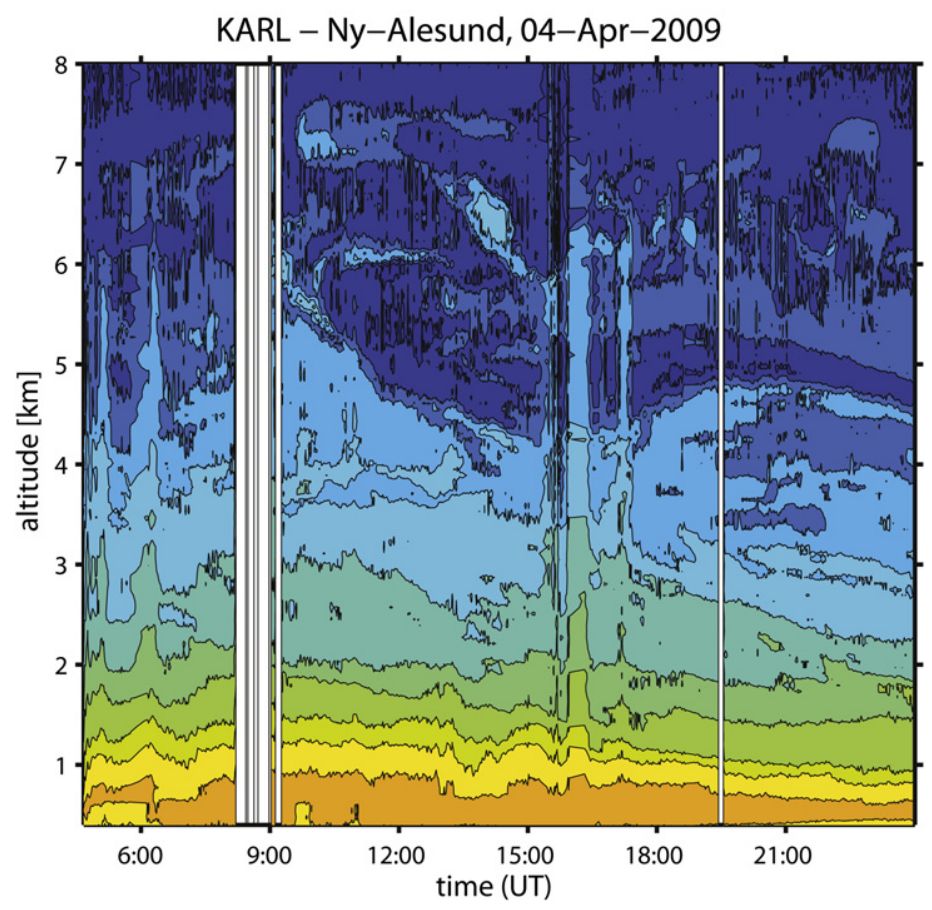

Res: $84 \mathrm{sec}, 60 \mathrm{~m}$

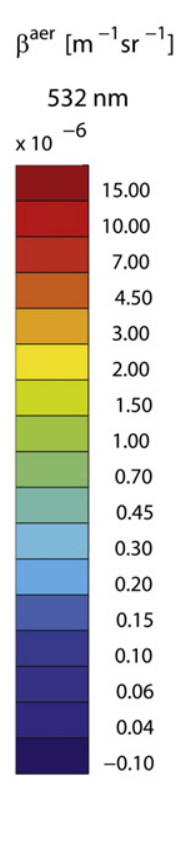

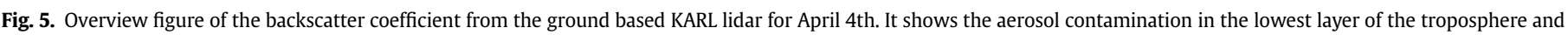
only a slow temporal variability. 


\section{a}

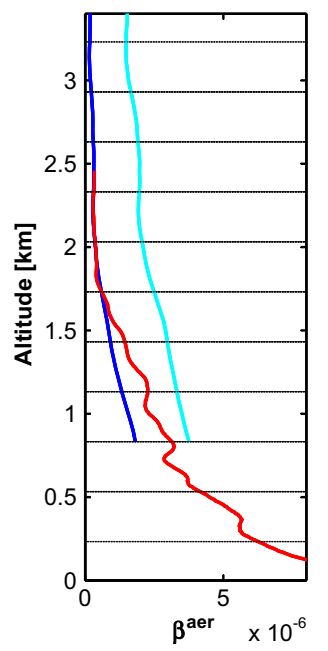

b

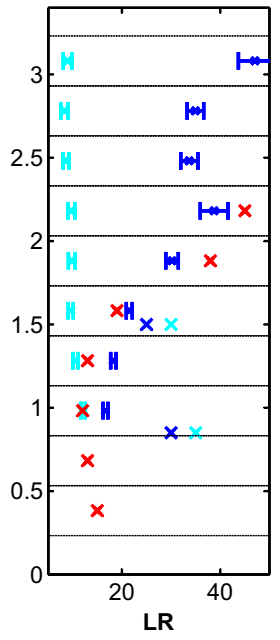

c

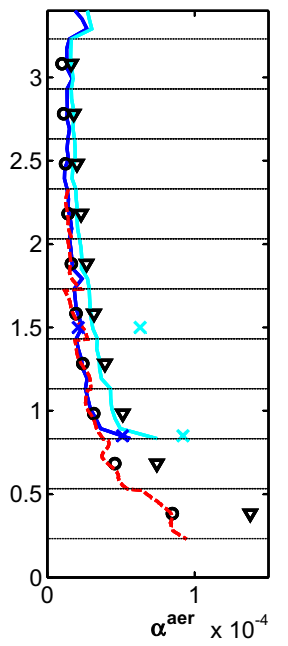

d

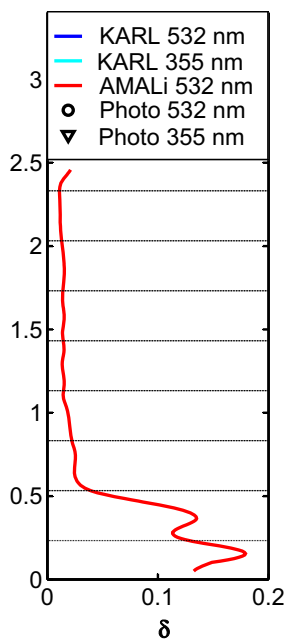

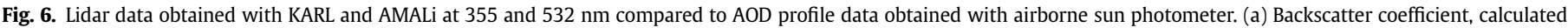

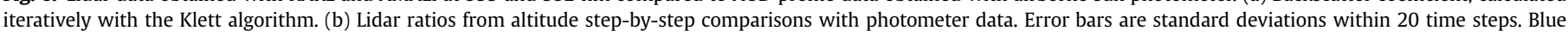

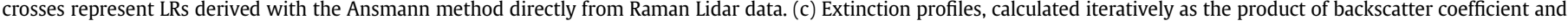

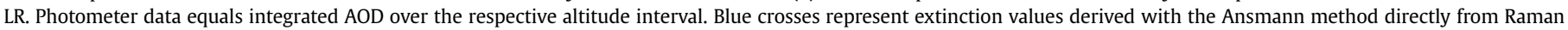
Lidar data. (d) Linear volume depolarization data at $532 \mathrm{~nm}$ as measured with AMALi.

Additionally, the extrapolated profiles at $532 \mathrm{~nm}$ and $355 \mathrm{~nm}$ are approximated by an exponential fit, as is illustrated in Fig. 7.

\subsection{Extinction and lidar ratios}

During the PAMARCMiP campaign extinction profiles were measured independently by two different systems: the airborne sun photometer, which obtained AOD data at different altitudes and the KARL Raman lidar. In the present data set, the extinction seen with the Raman lidar is higher than that in the photometer data especially in the UV, and hence, we briefly discuss both methods separately.

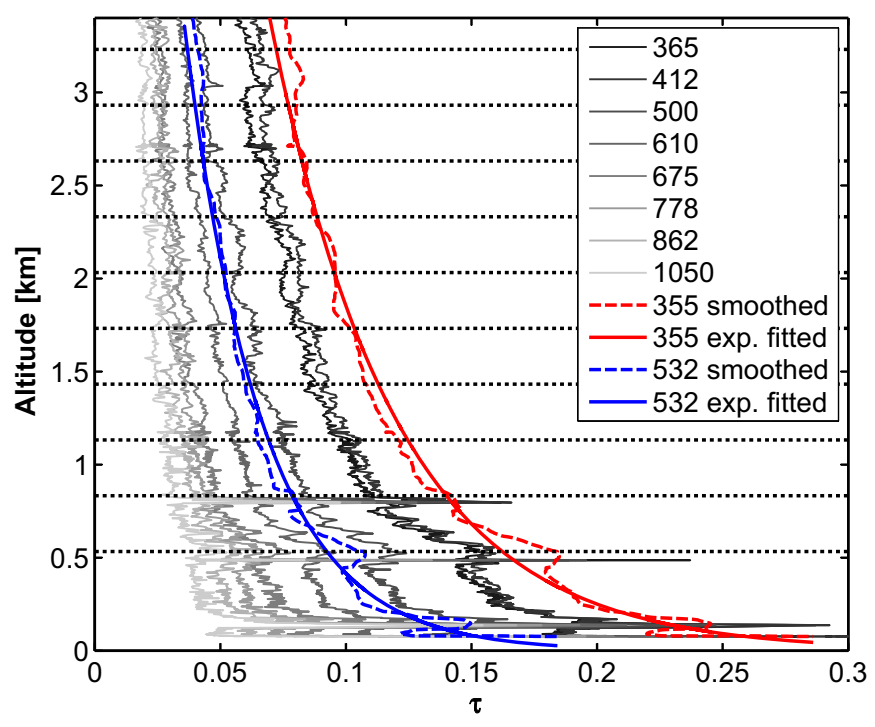

Fig. 7. AOD obtained with airborne sun photometer at eight different wavelengths. AOD at 355 and $532 \mathrm{~nm}$ was extrapolated using the Angström coefficient calculated from the 412 and 610-nm channel. The resulting data was smoothed and exponentially fitted. Dotted lines mark altitude intervals for extinction calculation.

\subsubsection{Photometer comparison}

As the AOD is the altitude integrated extinction, mean extinction values for selected altitude intervals can be calculated from the airborne photometer data (Fig. 6(c)). The selected altitude intervals are $300 \mathrm{~m}$ thick and range from about 0.2 to $3.2 \mathrm{~km}$. Results are given in Fig. 6(c). The lidar ratio usually varies with wavelength and altitude. However, here LR was set constant for each altitude interval and calculated as the ratio between aerosol extinction and mean backscatter coefficients in the respective interval. For this comparison backscatter profiles between 11:30 and 12:00 were averaged. Quite low LRs of about $10 \mathrm{sr}$ at $355 \mathrm{~nm}$ and $20 \mathrm{sr}$ at $532 \mathrm{~nm}$ have been found, the latter one increasing with altitude to $40 \mathrm{sr}$. These lidar ratios are significantly lower than otherwise reported for Arctic haze (Müller et al., 2007 and Ritter et al., 2004). Very similar LRs at $532 \mathrm{~nm}$ were derived from the AMALi backscattering and airborne photometer data. As the lidar ratio depends on size, chemical composition and shape of the aerosol, some variations with altitude can be expected. These low lidar ratios, together with the increasing volume depolarization below $1 \mathrm{~km}$ altitude, suggests that we did see some ice crystals next to the Arctic haze and generally only a small absorbing component. The results of the comparison are presented in Fig. 6(b).

\subsubsection{Raman method}

The combination of elastic wavelength detection and the detection of Raman scattering wavelengths allows vertical profiling of the aerosol extinction without a lidar ratio assumption, at least throughout the troposphere (Ansmann et al., 1992). Extinction values calculated from the 387 and $607 \mathrm{~nm} \mathrm{~N} \mathrm{~N}_{2}$ Raman cannels for two altitudes, one in within the wind shear layer at $850 \mathrm{~m}$ above sea level and one in the free troposphere at $1500 \mathrm{~m}$ are plotted in Fig. 6(c). These extinction values fairly agree with the photometer derived data at $532 \mathrm{~nm}$ but are more than twice as large at $355 \mathrm{~nm}$, and hence, lead to significantly larger LRs as can be seen in Fig. 6(b). Opposing to the method described above, here, the LRs at $355 \mathrm{~nm}$ are larger than at $532 \mathrm{~nm}$.

An overview on the derived LRs is given in Table 2. It can be seen that extinction and lidar ratio between lidar and photometer clearly 
Table 2

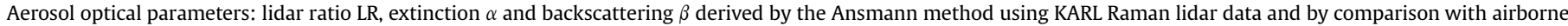

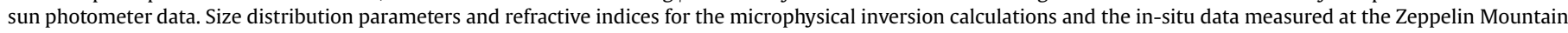

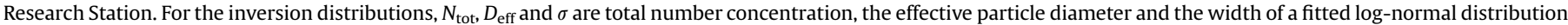

\begin{tabular}{|c|c|c|c|c|c|}
\hline & \multicolumn{2}{|l|}{ Raman lidar } & \multicolumn{2}{|c|}{ Sun photometer comparison } & \multirow{2}{*}{$\frac{\text { In-situ Zeppelin }}{474 \mathrm{~m}}$} \\
\hline & $850 \mathrm{~m}$ & $1500 \mathrm{~m}$ & $850 \mathrm{~m}$ & $1500 \mathrm{~m}$ & \\
\hline LR 355 [sr] & $33 \pm 5$ & $29 \pm 5$ & $12 \pm 5$ & $10 \pm 5$ & \\
\hline LR 532 [sr] & $30 \pm 5$ & $24 \pm 5$ & $17 \pm 5$ & $22 \pm 5$ & \\
\hline$\alpha_{355}\left[\mathrm{~m}^{-1}\right]$ & $9.2 \times 10^{-5}$ & $6.3 \times 10^{-5}$ & $2.8 \times 10^{-5}$ & $2.2 \times 10^{-5}$ & \\
\hline$\alpha_{532}\left[\mathrm{~m}^{-1}\right]$ & $5.1 \times 10^{-5}$ & $2.1 \times 10^{-5}$ & $3.3 \times 10^{-5}$ & $1.7 \times 10^{-5}$ & \\
\hline$\beta_{355}\left[\mathrm{~m}^{-1} \mathrm{sr}^{-1}\right]$ & $2.8 \times 10^{-6}$ & $2.2 \times 10^{-6}$ & $2.8 \times 10^{-6}$ & $2.2 \times 10^{-6}$ & \\
\hline$\beta_{532}\left[\mathrm{~m}^{-1} \mathrm{sr}^{-1}\right]$ & $1.6 \times 10^{-6}$ & $8.7 \times 10^{-7}$ & $1.6 \times 10^{-6}$ & $8.7 \times 10^{-7}$ & \\
\hline$\beta_{1064}\left[\mathrm{~m}^{-1} \mathrm{sr}^{-1}\right]$ & $3.0 \times 10^{-7}$ & $1.4 \times 10^{-7}$ & $3.0 \times 10^{-7}$ & $1.4 \times 10^{-7}$ & \\
\hline$m$ & \multicolumn{2}{|c|}{$(1.5-1.55)-(0.001-0.002) \mathrm{i}$} & \multicolumn{2}{|c|}{$(1.5-1.55)-(0.001-0.002) \mathrm{i}$} & \\
\hline$N_{\text {tot }}\left[\right.$ part. per $\mathrm{cm}^{3}$ ] & $207 \pm 40$ & $167 \pm 30$ & $33 \pm 5$ & $30 \pm 5$ & $400 \pm 50$ \\
\hline$D_{\text {eff }}[\mu \mathrm{m}]$ & $0.19 \pm 0.01$ & $0.17 \pm 0.01$ & $0.19 \pm 0.01$ & $0.15 \pm 0.01$ & $0.17-0.2$ \\
\hline$\sigma$ & $1.5 \pm 0.1$ & $1.5 \pm 0.1$ & $1.6 \pm 0.1$ & $1.4 \pm 0.1$ & \\
\hline
\end{tabular}

deviate. As the extinction in the Raman channels of the lidar surpass the extinction seen in the photometer data, the reproduction of the photometer extinction from elastic lidar data needs the assumption of lower LRs, especially at $355 \mathrm{~nm}$.

\subsection{Carbon measurements}

The carbon concentration is measured in-situ at the Zeppelin Mountain Research Station as well as on board the Polar 5. The airborne measurements obtained during the descent between 11 and 12 UTC reveal concentrations of $0.08 \pm 0.04 \mu \mathrm{g} \mathrm{m}^{-3}$ for altitudes up to $1100 \mathrm{~m}$. Above that altitude, concentrations fall to background values of $0.02 \pm 0.02 \mu \mathrm{g} \mathrm{m}^{-3}$. The data obtained at the Zeppelin Mountain is collected weekly, hence average values are measured. In week 14, from 30 March to 5 April, medium concentrations of elemental carbon EC $0.112 \mu \mathrm{g} \mathrm{m}^{-3}$ were recorded, which drop to 0.057 in the following week. EC measurements (performed by thermo optical analyzer) are usually found to be highly correlated with "equivalent BC concentrations" (obtained by aethalometer) (Ten Brink et al., 2004). The BC measurements by the aethalometer reveal an average concentration of $0.063 \pm 0.035 \mu \mathrm{g} \mathrm{m}^{-3}$ on 4 April, while during the latest $48 \mathrm{~h}$ before the 4 April it remained relatively stable at $0.055 \pm 0.013 \mu \mathrm{g} \mathrm{m}^{-3}$. These values are typical for this time of the year and very close to the ten year mean value for April at $0.062 \mu \mathrm{g} \mathrm{m}^{-3}$ reported by Eleftheriadis et al. (2009).

\subsection{Absorption and single scattering albedo}

The single scattering albedo can be calculated from the absorption data obtained at the Zeppelin Mountain Research Station. The aerosol extinction is estimated from the AOD profile obtained with airborne photometer and the Raman channels. From the extinction profile in Fig. 6(c) based on the photometer AOD, the extinction coefficients at the Zeppelin Mountain Research Station altitude amount to $0.7 \times 10^{-4} \mathrm{~m}^{-1}$ at $532 \mathrm{~nm}$ and $1.0 \times 10^{-4} \mathrm{~m}^{-1}$ at 355 . The in-situ absorption data from the PSAP are in the order of $1-2 \times 10^{-6}$, absorption coefficients estimated from the aethalometer results at $532 \mathrm{~nm}$ have an average value of $0.5 \times 10^{-6}$, resulting in a single scattering albedo of $0.97-0.99$. Since the photometer might underestimate the aerosol extinction as found above, the values can be taken as a lower limit, i.e. the single scattering albedo is very close to one, indicating aerosol particles with very weak absorption characteristics.

\subsection{Aerosol size distributions}

Aerosol size distributions have been obtained directly from DMPS measurements at $474 \mathrm{~m}$ altitude as well as from inversion calculations for spherical particles as described in Section 2.5. As input for the inversion the backscatter coefficients from the KARL lidar and 2 sets of extinction coefficients, from the lidar and from the photometer have been used. In this section the measured and derived size distribution will be compared. Two different altitudes have been selected from the remote sensing data to analyze possible gradients of aerosol properties with height.

The particle number concentrations obtained at the Zeppelin Mountain Research Station vary only slightly during the course of the day, with effective diameters ranging from 0.17 to $0.2 \mu \mathrm{m}$. Integrated number concentrations for particles larger than $0.1 \mu \mathrm{m}$ amount to $400 \pm 50 \mathrm{~cm}^{-3}$ (Fig. 8).

Based on the assumption of spherical aerosol particles, which is justified from 0.5 to $2.5 \mathrm{~km}$ ASL as determined from AMALi volume depolarization data at $532 \mathrm{~nm}$ (cf. Fig. 6(d)), inversion calculations were performed at two selected altitudes: one within the wind shear layer at $850 \mathrm{~m}$ and one in the free troposphere at $1500 \mathrm{~m}$. The calculations were performed with both, the low extinction values based on photometer data and the higher values based on Raman lidar data. For the retrieval of a size distribution from lidar data an index of refraction is determined, which is complicated as a lidar measures backscattering and extinction but not scattering or absorption. For our calculations the imaginary part of the refractive index was restricted to be smaller than 0.01 , as only little absorption

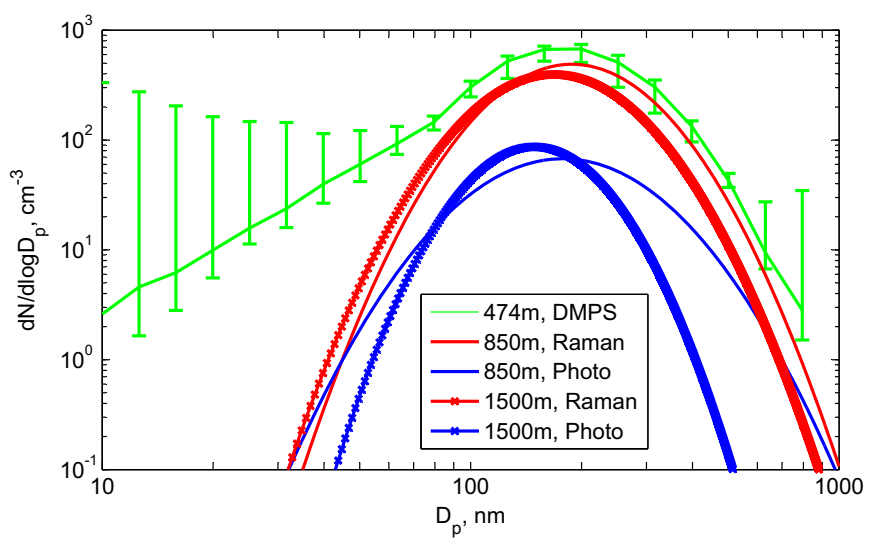

Fig. 8. Particle size distribution as measured by DMPS at the Zeppelin Mountain Research Station and as calculated with microphysical inversion from KARL and photometer data. The green curve represents the median concentration at the Zeppelin Mountain per bin during 4 April 2009. 10-90th percentiles are shown by the error bars. The blue and red curves were calculated according to the parameters given in Table 1. Note that the inversion distributions have been cut off for very small particles, as this reconstruction is to be highly problematic and usually dominated by artefacts and errors. 
was observed (see above). Using this restriction refractive indices with values between 1.5 and 1.55 in the real part and values between 0.001 and 0.002 in the imaginary part have been obtained for all four inversion runs. In Fig. 8, the resulting particle number distributions at $850 \mathrm{~m}$ and $1500 \mathrm{~m}$ altitude are plotted in comparison to the in-situ distribution. Below $100 \mathrm{~nm}$ diameter the scattering efficiency decreases sharply for visible light and, hence, no information can be retrieved for Aitken mode particles from optical data. While for all four distributions the effective diameter peaks at about $0.18 \mu \mathrm{m}$, the integrated number concentrations depend on the extinction assumption; i.e. higher extinction corresponds to larger number concentrations.

\section{Discussion}

AOD data obtained with airborne and ground based sun photometer show very stable enhanced values over the course of the day, which is also confirmed by the KARL lidar (Fig. 5). The airborne photometer measured slightly larger AODs although it did not include the first $100 \mathrm{~m}$ above ground. This might be due to the fact, that the Spitsbergen orography could have influenced, e.g. partly blocked, the constant northerly air flow to Ny-Ålesund, while the airplane's descent took place above the open ocean (cf. Fig. 1). The comparison of meteorological data obtained above Ny-Ålesund, at the Zeppelin Mountain Research Station and airborne by dropsonde and measurements on board Polar 5 reveals only slight changes within the area of interest. Two layers within the lower troposphere could be identified. The lowermost layer stretches from the ground to about $500 \mathrm{~m}$ altitude and is characterized by easterly winds, constant potential temperature and relatively humidity below $60 \%$. Additionally, scattering in this layer is connected with enhanced volume depolarization; hence, particles are assumed to be aspherical and may have a component of local origin, e.g. sea salt aerosol from the non sea ice covered fjord. The second layer extends up to about $1100 \mathrm{~m}$ and features a change in wind direction from East to North at very low wind speeds. Hence, aerosols in this layer and above are probably resulting from long-range transport from the inner Arctic. Compared to the free troposphere, water vapor mixing ratio and black carbon concentrations are only slightly enhanced with $0.7 \mathrm{~g} \mathrm{~kg}^{-1}$ and $0.08 \mu \mathrm{g} \mathrm{m}^{-3}$, respectively.

As the disagreement in extinction profiles between the lidar and the photometer data was so pronounced, size distribution calculations were performed for both data sets. The comparison of KARL backscatter and airborne photometer AOD data revealed very small lidar ratios of $10 \mathrm{sr}$ at 355 and $20 \mathrm{sr}$ at $532 \mathrm{~nm}$ (cf. Fig. 6). In contrast, direct extinction measurements from the KARL Raman channels reveal larger LRs in the order of $30 \mathrm{sr}$ at both wavelengths, which are closer to values derived for Arctic haze before (Ritter et al., 2004 and Hoffmann et al., 2009, both with Ansmann method). This revealed discrepancy is remarkable, since photometer AOD is often used to confirm lidar observations. Several possible reasons are conceivable. First, instrumental reasons, e.g. the different fields of view, can be considered: Due to their larger field of view the photometers might have collected more multiple scattering. Radiation which remains in the field of view increases the measured photo current and hence decreases the measured AOD. However, the atmospheric turbidity measured here does not exceed values at populated sites elsewhere and hence we don't have hints for systematic measurement bias in the photometer. Overlap problems in the lidar data can be excluded for two reasons: First, the effect of a low lidar ratio close to the ground is seen in both, the airborne and the ground based lidar. Second, the backscatter in the ground based lidar can be calculated by the elastic signal alone (Klett, 1981) or by the Ansmann method (Ansmann et al., 1992) which hardly depends on the overlap. As both methods yield the same result, complete overlap must have been reached at $850 \mathrm{~m}$ altitude. Different atmospheric conditions as a reason for extinction discrepancies are possible since the airborne measurements at low altitudes took place north of Prins Karls Foreland and not directly in the vicinity of Ny-Ålesund. However, since both the ground based sun photometer and the KARL lidar recorded only small temporal variations of the aerosol content and the ground based photometer confirmed the low AODs seen in the airborne photometer data, this seems to be unlikely as well. Another possibility is a slightly different approach to subtract Rayleigh scattering from the signals. In case of the photometer data, an approach of Fröhlich and Shaw (1980) was employed, while for the Raman lidar data, Rayleigh scattering was considered according to Bucholtz (1995). Although for the UV the index of refraction considered in both methods is almost identical, a 10\% lower Rayleigh optical depth for $365 \mathrm{~nm}$ results. As the molecular scattering in the UV surpasses the aerosol scattering, this can increase the AOD, e.g. in our case between 800 and $1700 \mathrm{~m}$ altitude from 0.04 to 0.046 (lidar: 0.07). Hence, only about $20 \%$ of the total deviation can be ascribed to the different treatment of molecular scattering. For this reason we have to assume that passive and active remote sensing instruments reacted differently to the meteorological conditions.

Meteorological data suggest that the Zeppelin Mountain Research Station was within the lowest mixing layer or possibly at the transition zone. Aerosol size distributions from DMPS data collected at the Zeppelin Mountain show small diameters of about $0.17-0.2 \mu \mathrm{m}$ and total number concentrations of about 400 particles per $\mathrm{cm}^{3}$. Since almost no coarse mode particles have been found, aerosols from local sources have probably not been present at this altitude. A high single scattering albedo of 0.97-0.99 and low black carbon concentrations indicate that only non-absorbing aerosol components were present. These are typical values for Arctic haze, which is usually composed of sulfates with only a minor soot component (Quinn et al., 2000 and Yamanouchi et al., 2005).

Lidar data have been inverted for the retrieval of aerosol size distributions. These calculations were carried out at different altitudes: $850 \mathrm{~m}$ in the wind shear layer and $1500 \mathrm{~m}$ in the free troposphere. Similar distributions as measured in-situ at the Zeppelin Mountain Research Station have been found, with lower particle concentrations at higher altitudes for both extinction data sets (cf. Table 2 and Fig. 8). While in the in-situ size distributions, total number concentrations of 400 particles per $\mathrm{cm}^{3}$ have been found, the inversion calculations reveal 167 to 207 particles per $\mathrm{cm}^{3}$ based on Raman lidar extinction and only 30 to 33 particles per $\mathrm{cm}^{3}$ based on photometer extinction. In fact, the lower number concentrations are the most distinct difference between both inversion runs. As discussed above, influences of local aerosols should be minor at the altitude of the Zeppelin station and negligible at higher altitudes. Moreover, the relative humidity, which determines the hygroscopic growth of aerosol, did not vary largely and did not exceed $60 \%$ at the considered altitudes. Above $500 \mathrm{~m}$, the same long-range transported aerosol was probably present at all altitudes. Additionally, particle diameters in the observed size range $(D=0.15-0.20 \mu \mathrm{m})$ resemble those with the longest lifetime in the troposphere. Generally, the inversions show that the aerosols detected above the Zeppelin Mountain Research Station fairly agree to the in-situ measured aerosols at $474 \mathrm{~m}$ altitude in terms of size distribution function and refractive index. A slight gradient of particle diameter with altitude can be seen, which might be expected for aged, undisturbed aerosols since larger particles are influenced stronger by gravitational sinking. For aerosol in the accumulation mode the sedimentation velocity $\left[\mathrm{m} \mathrm{s}^{-1}\right.$ ] depends on the radius $[\mu \mathrm{m}]$ and is approximately (Twomey, 1977):

$v=\left(\frac{r}{8.5}\right)^{2}$ 
For each method, the derived size distributions are quite similar for both altitudes, with the photometer based distribution in $850 \mathrm{~m}$ altitude being slightly narrower than the other ones. This effect also leads to a less trustworthy reproduction of the right slope of the in-situ distribution. As expected from the backscatter profile, particle concentrations decrease with altitude, coinciding with a slight decrease in the effective diameter. However, since the narrower photometer based distribution reveal rather low total particle number concentrations which imply a decrease by a factor of 10 from $474 \mathrm{~m}$ altitude to $1500 \mathrm{~m}$ while particle backscatter only decreases by a factor of four (cf. Fig. 6(a), AMALi backscatter profile), and the derived lidar ratios in the order of $10 \mathrm{sr}$ in the UV seem unlikely low, the Raman method leads to the more probable inversion. In all cases, weakly absorbing particles have been identified. This is supported by the airborne measured black carbon concentrations, which, although being significantly larger within the two identified layers, do not show unusually large values.

\section{Summary}

For the first time, according to our knowledge, a comparison of microphysical aerosol properties derived from in-situ and remote sensing data was performed in the European high Arctic was given. With 4 April 2009, a day with increased aerosol load and quite stable meteorological conditions during the 2009 PAMARCMiP campaign was chosen.

It has been shown, that by combining the presented data sets, an overview on the meteorological situation as well as the optical and microphysical properties of aerosols present within the lower troposphere could be given. The spatial distance of the different measurements as well as the different altitude intervals in which the aerosol was probed might be of concern. However, since the meteorological situation was stable, the time frame of about $2 \mathrm{~h}$ and the spatial distances covered of about $20 \times 40 \mathrm{~km}$ still guarantee probing of the same air mass. This has been proven by the fact, that the identified two-layer-structure of the lower troposphere was captured by the two meteorological soundings as well the AMALi and the airborne BC data. The airborne lidar and photometer measurements provide the link between the KARL lidar data and the Zeppelin Mountain Research Station at $474 \mathrm{~m}$ altitude, although direct comparison of lidar derived size distributions at this altitude was not possible due to overlap issues.

In our data, a remarkable difference between the extinction values derived from photometer AOD profiles (lower values) and Raman lidar data (higher values), especially for the UV has been found. This difference has been discussed and needs to be taken care of when lidar data are compared to or calibrated using photometer based extinction data. Nevertheless, aerosol size distributions calculated from lidar data combined with extinction values from both methods have been derived at two altitudes $(850 \mathrm{~m}$ and $1500 \mathrm{~m}$ ). The differences between both extinction data sets lead to only minor variations in the refractive index (around 1.52-0.0015i) and in the size distributions width and effective diameters. The solution based on the larger extinction compares relatively well with the in-situ aerosol size distribution from DMPS data obtained at the Zeppelin Mountain Research Station at $474 \mathrm{~m}$ altitude. The solution based on the lower extinction shows a quite narrow size distribution at $850 \mathrm{~m}$ and too little total number concentrations albeit the same effective diameter. Hence, from the differences in the derived lidar ratios, the number concentration discrepancy and the reproduction of the right slope of the in-situ size distribution curve, the higher extinction values from the Raman lidar seem to be closer to reality and just match those measured in-situ. If we simply scale the result for the inversion of the KARL lidar at $850 \mathrm{~m}$ altitude to the height of the Zeppelin station, using the backscatter profile from AMALi in
Fig. 6(a), we derive approximately $300 \pm 60$ particles per $\mathrm{cm}^{3}$ in the lidar, compared to $400 \pm 50$ particles per $\mathrm{cm}^{3}$ in the in-situ instrument. All distributions peak in the accumulation mode at a diameter of about $0.18 \mu \mathrm{m}$ with distribution heights decreasing with altitude. The results indicate that the same aerosol with similar size distribution in the accumulation mode and only a small absorbing fraction was observed at the different altitudes. This was also confirmed by low $\mathrm{BC}$ concentrations and a high single scattering albedo derived from the in-situ absorption measurements. The aerosol load was largest in the lower troposphere decreasing with altitude and was advected from the inner Arctic.

Concluding, Ny-Ålesund with its various ground based facilities and the Zeppelin Mountain Research Station provides an interesting platform to proceed with this kind of in-situ versus remote sensing data comparisons to increase our knowledge on Arctic aerosol and its impact on climate. Besides upcoming follow-up campaigns of the PAMARCMiP project, the ground based instrumentation is currently upgraded, e.g. a second photometer is installed directly at the Zeppelin Mountain Research Station and the KARL lidar will be used frequently in a boundary layer measurement configuration.

\section{Acknowledgments}

We would like to thank the PAMARCMiP crew as well as the AWIPEV Base personnel, whose effort provided the present comprehensive data set. We would like to thank NILU for the access to the meteorological data at the Zeppelin Mountain Research Station. Furthermore, we acknowledge the support from Holger Deckelmann and Alexander Schulz in data preparation.

\section{References}

Ansmann, A., Riebesell, M., Wandinger, U., Weitkamp, C., Voss, E., Lahmann, W. Michaelis, W., 1992. Combined Raman elastic-backscatter LIDAR for vertical profiling of moisture, aerosol extinction, backscatter, and LIDAR ratio. Applied Physics B Photophysics Laser Chemistry 55, 18-28.

Barrie, L., Hoff, R., Daggupaty, S., 1981. The influence of mid-latitudinal pollution sources on haze in the Canadian Arctic. Atmospheric Environment 15 (8), 1407-1419.

Böckmann, C., Kirsche, A., 2006. Iterative regularization method for lidar remote sensing. Computer Physics Communications 174, 607-615.

Bucholtz, A., 1995. Rayleigh-scattering calculations for the terrestrial atmosphere. Applied Optics 34, 2765-2773.

Eleftheriadis, K., Vratolis, S., Nyeki, S., 2009. Aerosol black carbon in the European Arctic: measurements at Zeppelin station, Ny-Ålesund, Svalbard from 1998-2007. Geophysical Research Letters 36, L02809. doi:10.1029/2008GL035741.

Fröhlich, C., Shaw, Glenn E., 1980. New determination of Rayleigh scattering in the terrestrial atmosphere. Applied Optics 19, 1773-1775.

Gerding, M., Ritter, C., Müller, M., Neuber, R., 2004. Tropospheric water vapor soundings by lidar at high Arctic latitudes. Atmospheric Research 71 (4), 289-302.

Herber, A., Thomason, L., Gernandt, H., 2002. Continuous day and night aerosol optical depth observations in the Arctic between 1991 and 1999. Journal of Geophysical Research (Atmospheres) 107, 4097.

Hoffmann, A., Ritter, C., Stock, M., Maturilli, M., Eckhardt, S., Herber, A., Neuber, R. 2010. Lidar measurements of the Kasatochi aerosol plume in August and September 2008 in Ny-Ålesund, Spitsbergen. Journal of Geophysical Research (Atmospheres) 115, D00L12.

Hoffmann, A., Ritter, C., Stock, M., Shiobara, M., Lampert, A., Maturilli, M., Orgis, T. Neuber, R., Herber, A., 2009. Ground-based lidar measurements from Ny-Ålesund during ASTAR 2007. Atmospheric Chemistry \& Physics 9, 9059-9081.

Klett, J., 1981. Stable analytical inversion solution for processing lidar returns Applied Optics 20, 211-220.

Knutson, E.O., Whitby, K.T., 1975. Aerosol classification by Electrical mobility: apparatus, Theory, and Applications. Journal of Aerosol Science 6, 443-451.

Law, K., Stohl, A., 2007. Arctic air pollution: origins and impacts. Science 315 (5818), 1537-1540. doi:10.1126/science.1137695.

Liu, Y., Ackerman, S.A., Maddux, B.C., Key, J.R., Frey, R.A., 2010. Errors in cloud detection over the Arctic using a satellite imager and implications for observing feedback mechanisms. Journal of Climate 23 (7), 1894-1907.

Müller, D., Ansmann, A., Mattis, I., Tesche, M., Wandinger, U., Althausen, D. Pisani, G., 2007. Aerosol-type-dependent lidar ratios observed with Raman lidar. Journal of Geophysical Research (Atmospheres) 112 (D16), D16202.

Orgis, T., Brand, S., Schwarz, U., Handorf, D., Dethloff, K., Kurths, J., 2009. Influence of interactive stratospheric chemistry on large-scale air mass exchange in a global circulation model. The European Physical Journal - Special Topics 174 (1), 257-269. 
A. Hoffmann et al. / Atmospheric Environment xxx (2012) 1-11

11

Osterloh, L., Böckmann, C., 2009. Microphysical properties and distribution retrieval with a variable base point algorithm. Proceedings of SPIE 7475 (2009), 1-8.

Osterloh, L., Pérez, C., Böhme, D., Baldasano, J.M., Böckmann, C., Schneidenbach, L. Vicente, D., 2009. Parallel software for retrieval of aerosol distribution from lidar data in the framework of EARLINET-ASOS. Computer Physics Communications 180 (2009), 2095-2102.

Quinn, P., Bates, T., Miller, T., Coffman, D., Johnson, J., Harris, J., Ogren, J., Forbes, G., Anderson, T., Covert, D., et al., 2000. Surface submicron aerosol chemical composition - what fraction is not sulfate? Journal of Geophysical Research 105, 6785-6805.

Quinn, P., Shaw, G., Andrews, E., Dutton, E., Ruoho-Airola, T., Gong, S., 2007. Arctic haze: current trends and knowledge gaps. Tellus Series B Chemical and Physical Meteorology B 59, 99-114.

Rahn, K., Borys, R., Shaw, G., 1977. The Asian source of Arctic haze bands. Nature 268, 713-715.

Rahn, K., 1981. Relative importances of North America and Eurasia as sources of Arctic aerosol. Atmospheric Environment 15 (8), 1447-1455.

Ritter, C., Kirsche, A., Neuber, R., 2004. Tropospheric aerosol characterized by a Raman lidar over Spitsbergen. In: Proceedings of the 22nd International Laser Radar Conference (ILRC 2004), Matera, Italy, vol. 1, pp. 459-462.

Shaw, G., 1995. The Arctic haze phenomenon. Bulletin of the American Meteorological Society 76, 2403-2414.

Sirois, A., Barrie, L., 1999. Arctic lower tropospheric aerosol trends and composition at Alert, Canada: 1980-1995. Journal of Geophysical Research 104 (D9), 11599.

Stachlewska, I.S., Neuber, R., Lampert, A., Ritter, C., Wehrle, G., 2010. AMALi - the airborne mobile aerosol lidar for Arctic research. Atmospheric Chemistry and Physics 10, 2947-2963.

Stohl, A., 2006. Characteristics of atmospheric transport into the Arctic troposphere. Journal of Geophysical Research 111 (D11), D11306.

Stone, R. S. (2002), Monitoring aerosol optical depth at Barrow, Alaska and South Pole; Historical overview, recent results, and future goals, Proceedings of the 9th Workshop Italian Research on Antarctic Atmosphere, Rome, Italy, 22-24 October 2001, edited by M. Colacino, pp. 123-144, Ital. Phys. Soc., Bologna, Italy, http://www.cmdl.noaa.gov/hotitems/Porano9EXTabs.pdf.
Stone, R., Herber, A., Vitale, V., Mazzola, M., Lupi, A., Schnell, R., Dutton, E., Liu, P., Li, S., Dethloff, K., et al., 2010. A three-dimensional characterization of Arctic aerosols from airborne Sun photometer observations: PAM-ARCMIP, April 2009. Journal of Geophysical Research 115 (D13), D13203.

Ström, J., Umegard, J., Tørseth, K., Tunved, P., Hansson, H.C., Holmén, K., Wismann, V., Herber, A., König-Langlo, G., 2003. One year of particle size distribution and aerosol chemical composition measurements at the Zeppelin Station, Svalbard, March 2000-March 2001. Physics and Chemistry of the Earth, Parts A/B/C 28, 1181-1190.

Ten Brink, H., Maenhaut, W., Hitzenberger, R., Gnauk, T., Spindler, G., Even, A., Chi, X., Bauer, H., Puxbaum, H., Putaud, J., Tursic, J., Berner, A., 2004. INTERCOMP2000: the comparability of methods in use in Europe for measuring the carbon content of aerosol. Atmospheric Environment 38 (38), 6507-6519.

Twomey, S., 1977. Atmospheric Aerosols. Elsevier Scientific Publishing Co., New York, NY, ISBN 978-0444415271.

Wandinger, U., Müller, D., Böckmann, C., Althausen, D., Matthias, V., Bösenberg, J., Weiß, V., Fiebig, M., Wendisch, M., Stohl, A., Ansmann, A., 2002. Optical and microphysical characterization of biomass-burning and industrial-pollution aerosols from multiwavelength lidar and aircraft measurements. Journal of Geophysical Research 107 (D21), 8125. doi:10.1029/2000JD000202.

Warneke, C., Froyd, K.D., Brioude, J., Bahreini, R., Brock, C.A., Cozic, J., de Gouw, J.A., Fahey, D.W., Ferrare, R., Holloway, J.S., Middlebrook, A.M., Miller, L., Montzka, S.A., Schwarz, J.P., Sodemann, H., Spackman, R., Stohl, A., 2010. An important contribution to springtime Arctic aerosol from biomass burning in Russia. Geophysical Research Letters 37 (1), L01801. doi:10.1029/ 2009GL041816.

Wiedensohler, A., 1988. An approximation of the bipolar charge distribution for particles in the submicron size range. Journal of Aerosol Science 19 (3), 387-389.

Yamanouchi, T., Treffeisen, R., Herber, A., Shiobara, M., Yamagata, S., Hara, K., Sato, K., Yabuki, M., Tomikawa, Y., Rinke, A., Neuber, R., Schumacher, R., Kriews, M., Ström, J., Schrems, O., Gernandt, H., 2005. Arctic Study of Tropospheric Aerosol and Radiation (ASTAR) 2000: arctic haze case study. Tellus Series B Chemical and Physical Meteorology B 57, 141.

Please cite this article in press as: Hoffmann, A., et al., Remote sensing and in-situ measurements of tropospheric aerosol, a PAMARCMiP case study, Atmospheric Environment (2012), doi:10.1016/j.atmosenv.2011.11.027 